\title{
The need for intercultural sensitivity: A frontline report of a German probation officer
}

International Social Work 2018, Vol. 6I(2) 308-31I

(C) The Author(s) 2016 Reprints and permissions: sagepub.co.uk/journalsPermissions.nav DOI: I0.II77/00208728I6664966 journals.sagepub.com/home/isw

@SAGE

\section{Christian Ghanem}

Ludwig-Maximilians-Universität München, Germany

\begin{abstract}
In this contribution, a German probation officer provides some critical reflections and argues for an increasing need to enhance intercultural sensitivity among probation officers. If the probation service wants to avoid contributing to the social exclusion of its clients, changes on an educational, organizational and political level are necessary.
\end{abstract}

\section{Keywords}

Criminal justice, Germany, intercultural sensitivity, migration, offenders, probation

\section{Migration and the German probation service}

Social workers in many countries are increasingly confronted with clients with migrant backgrounds due to the vast growth of displaced persons. According to the United Nations High Commissioner for Refugees (UNHCR, 2016), around 65 million persons are displaced, an increase of around 50 percent during the last four years. This development has also had an effect on Germany, where the number of asylum seekers has more than doubled from 2014 to 2015 (Bundesamt für Migration und Flüchtlinge, 2016). Many of the asylum seekers in Germany are already social work service users, especially in directly related fields like migration counselling. However, we can also expect a rise of non-German clients within the context of the probation service, where I am employed as a social worker. I do not want to claim that migrants in Germany commit more crimes than German-born citizens. Despite the fact that they are disproportionally affected by processes of illegalization and criminalization (Parkin, 2013), and confronted with circumstances which statistically increase the likelihood of deviant behaviour (e.g. for substance abuse, cf. Borges et al., 2007), current evidence shows that these people do not commit more crimes compared to German-born citizens (Bundeskriminalamt, 2016). Nevertheless, we can expect that the mentioned risk factors they are facing as well as the increasing number of migrants will lead to a growing amount of nonGerman clients within the probation service. Some critical observations during my work in the 
probation service and the outlined development have raised my interest in the following question: Which specific challenges occur when probation service clients are also migrants?

\section{Challenges for migrants and the probation officers}

In this section I want to elaborate on specific challenges occurring when probation service clients are also migrants. These challenges are based on my own personal observations while working in the probation service and on some critical reflections triggered by specific incidents.

The most obvious challenge occurs due to language barriers between the probation officer and the client. Some clients either do not or rarely speak German. This is the reason why the judge often decides against supervision by a probation officer. For instance, I once had a client who arrived as an unaccompanied minor refugee from Afghanistan. He was convicted of grievous bodily harm, experienced a lot of violence himself in his past and seemed to have pretty low practical life skills, at least in terms of his self-management in a foreign country. Some months after his release, the judge wanted to end the probation supervision due to the client's low German skills. This was a crucial moment for me because I realized that an indicator of needing support can lead to a withdrawal of support. Of course, the opportunities of social work interventions are limited when the client does not speak the same language. In this case, however, I could convince the judge to keep the supervision and offered the client a voluntary probation officer who had the time to go with him to the job centre and the immigration office and to support him in looking for a flat. To support somebody in fulfilling these basic needs does not necessarily require that both people speak the same language.

Given the case that a client has sufficient German skills, there are additional barriers in terms of legal language. Legal language is very hard to 'decode'. In the first year of my work in the probation service it was hard even for me to understand such language used in, for instance, court judgments or court orders. For many clients who have migrated from other countries that do not speak German, it is nearly impossible to fully understand the content of the court hearings or the written court letters. This misunderstanding can cause serious consequences. The court orders formulate how the client has to behave during the probation period. These orders directly influence and often limit their fundamental rights, and if they do not understand these orders, the chance of incarceration is pretty high. Hence, a central responsibility of my professional work was to translate the legal and administrative language into an everyday language and to explain the basic principles of our justice system to clients who have not grown up in Germany.

Another issue arises from cultural-specific communication barriers. The interaction between a social worker and a client with a different cultural background and often conflicting cultural standards (Thomas, 2010) can be demanding for both sides. For instance, a problem-centred interview or confrontational approaches might cause reluctance among clients who are not used to such direct communication. Furthermore, I remember a situation in which I reacted with reluctance because a Somalian client asked how my wife and my family were doing. Since German social workers are trained to keep personal distance from the client, such questions might be found irritating.

Besides the cultural influence on the professional work on an individual basis, I claim that the scientific knowledge underlying our professional work also reflects a Eurocentric or Westerncentric perspective, and leads to the neglect of non-Western norms and values. Social work practice is increasingly influenced by research evidence (Okpych and Yu, 2014). This is also true for the German probation service, which is indicated by the rise of practice evaluations (e.g. Haverkamp and Walsh, 2014) or the implementation of risk assessment tools. These tools are usually based on criminological research evidence generated in North America (e.g. Andrews and Bonta, 2010). This is one indicator that the research practice neglects the Global South and that Henrich et al.'s 
(2010) observation might be transferable to social work. They claim that most psychological research is conducted in Western, educated, industrialized, rich, democratic (WEIRD) societies. Therefore, it can be questioned whether these research results are still valid when applied in the context of social work with persons from, for instance, African or Asian countries, in probation services in those countries.

Regarding the concrete utilization of risk assessment tools, additional issues might occur in intercultural social work settings. I want to illustrate this by means of an example from my probation practice. My employer requires probation officers to apply a risk assessment tool, which serves as a basis to categorize the client by means of different factors. I had to apply binary codes, for instance, regarding whether or not the client has self-reflection skills (Beß and Koob-Sodtke, 2007: 253). In addition to the issue that the scientific generation of those risk factors might be culturally biased, the application necessarily requires a hermeneutical judgement of subjects embedded in their individual cultural circumstances. I have often had the impression that clients with more collectivistic cultural backgrounds do not feel comfortable speaking about themselves and avoid reflecting on individual factors, which might have caused their deviant behaviour. Do those clients have to be labelled as possessing 'no self-reflection skills'? Should the concrete operationalization of the risk factors differ according to the cultural background? Such questions are demanding for the individual probation officer and require high sensibility in terms of intercultural topics, which leads me to some concluding implications for the field of probation service and beyond.

\section{Conclusion and implications}

The outlined examples from my professional experience in the German probation service suggest that the recent findings of Krumer-Nevo et al. (2016) might also be evident in German cultural contexts. They found that the correctional services in Israel enhance processes of social exclusion. Although they identified causes beyond intercultural topics, they emphasize the conflict of the client's (sub-)culture and the mainstream culture (p. 43). Hence, the outlined challenges resulting from intercultural differences might serve as further drivers for exclusion processes increased in the name of social work. To counteract those phenomena, and more specifically to master the concrete challenges described above, I see a vast need to increase intercultural sensibility in many dimensions. First, it is important to implement intercultural training at both universities and courts, where probation officers are employed. Although there are plenty of further education opportunities for probation officers, I have never seen training courses regarding intercultural topics. If an individual probation officer wants to attend those training courses, he or she usually has to use personal resources. I believe that increasing participation in such training will lead to an increase of interculturally sensitive professionals. At the university where I completed my undergraduate studies, there were interesting courses focused on enabling students to develop intercultural competence. However, there was no mandatory seminar focusing on related topics. Since social workers have to work with migrants in all professional fields, it would be important to implement intercultural training in the curricula. This is necessary not only to develop appropriate reflection skills regarding intercultural interactions, but also regarding cultural hegemony embedded in the scientific knowledge we are confronted with. Given the fact that more and more migrants are among our clients, it is also important to mention related skills in job descriptions, which is still rarely done. In my opinion, efforts to enhance intercultural sensitivity among probation officers are the prerequisites to ensure equal opportunities for all clients. Even though I can only provide reflections on my own professional experiences in the probation service, the described issues might also be evident in other fields of social work. Social workers in fields related to correctional services might additionally be confronted with contradicting political interests. Since the political 
mainstream in many countries is not in favour of spending more money on improving services for criminal migrants, I see a clear political mandate to stand up for the interests of our clients and counteract the structural handicap of those clients. In this regard, I want to end this contribution with some admonitory words formulated by Krumer-Nevo et al. (2016):

$[\ldots]$ the educational and correctional services [...], [are] manifesting institutional blindness in connection with the youth and hence contributing to the double exclusion of young men. [...] Inclusion cannot exist if the community does not want to, or is not prepared to integrate young men within it. (pp. 36, 49)

\section{Funding}

The author(s) received no financial support for the research, authorship and/or publication of this article.

\section{References}

Andrews, D.A. and J. Bonta (2010) The Psychology of Criminal Conduct, 5th edn. Albany, NY: Lexis Nexis/ Anderson.

Beß, K. and G. Koob-Sodtke (2007) 'Der Kontroll- und Unterstützungsprozess in der Bewährungshilfe in Bayern' [The Control and Support Process in the Probation Service], Bewährungshilfe 54(3): 249-57.

Borges, G., M.E. Medina-Mora, J. Breslau and S. Aguilar-Gaxiola (2007) 'The Effect of Migration to the United States on Substance Use Disorders among Returned Mexican Migrants and Families of Migrants', American Journal of Public Health 97(10): 1847-51.

Bundesamt für Migration und Flüchtlinge (2016) 'Das Bundesamt in Zahlen 2015 - Asyl' [The Federal Office in Numbers 2015 - Asylum]. Available online at: http://www.bamf.de/SharedDocs/Anlagen/DE/ Publikationen/Broschueren/bundesamt-in-zahlen-2015-asyl.pdf?_blob=publicationFile

Bundeskriminalamt (2016) 'Kriminalitätsentwicklung im Zusammenhang mit Zuwanderung' [Criminality Development in Relation with Immigration]. Available online at: http://www.bmi.bund.de/SharedDocs/ Kurzmeldungen/DE/2016/06/bka-lagebild-kriminalitaet-zuwandeung.html

Haverkamp, R. and M. Walsh (2014) 'Intensivbewährungshilfe bei jugendlichen und heranwachsenden Intensiv- und Mehrfachtätern: Erste Ergebnisse der wissenschaftlichen Begleitforschung des Modellprojekts RUBIKON' [Intensive Probation Service with Juvenile and Adolescent High-Risk Offenders: First Results of a Scientific Accompanying Research of the Pilot Project RUBIKON], Bewährungshilfe 61(2): 117-31.

Henrich, J., S.J. Heine and A. Norenzayan (2010) 'The Weirdest People in the World?', Behavioral and Brain Sciences 33(2-3): 61-83.

Krumer-Nevo, M., Y. Elfassi, S. Sagy and M. Lavie-Ajayi (2016) 'Neither Seeing Nor Seen: Exclusion and Double Exclusion in the Lives of Young People Involved in the Drug Trade in Israel', Young 24(1): $36-52$.

Okpych, N.J. and J.L.-H. Yu (2014) 'A Historical Analysis of Evidence-based Practice in Social Work: The Unfinished Journey Toward an Empirically Grounded Profession', Social Service Review 88(1): 3-58.

Parkin, J. (2013) 'The Criminalisation of Migration in Europe: A State-of-the-Art of the Academic Literature and Research', CEPS Paper in Liberty and Security in Europe: No. 61. Brussels: Centre for European Policy Studies.

Thomas, A. (2010) 'Culture and Cultural Standards', in E.-U. Kinast, S. Schroll-Machl, A. Thomas and C. Weston-Horsmann (eds) Handbook of Intercultural Communication and Cooperation: Basics and Areas of Application, 2nd edn, pp. 17-27. Göttingen: Vandenhoeck \& Ruprecht.

United Nations High Commissioner for Refugees (UNHCR) (2016) 'Global Trends: Forced Displacement in 2015'. Available online at: http://www.unhcr.org/global-trends-2015.html

\section{Author biography}

Christian Ghanem is a probation officer at the county court in Munich, Germany. Currently, he is on special leave to work on a $\mathrm{PhD}$ at the Ludwig-Maximilians-Universität München as well as a social work lecturer at the Katholische Stiftungsfachhochschule München. 